\section{A BUMPER ISSUE, TOUCHING ON SARS, HEALTH IMPACT ASSESSMENT, AND MUCH \\ ELSE}

According to Martyn Regan, "capturing, remembering, and learning from these experiences will enable the wider international community to be better prepared for not only SARS, but also for the next emerging infection that we will undoubtedly have to face in the future". Regan is writing about his visit to Canada as part of a group appraising the reaction to SARS in that country. We try to make our own contribution to learning from SARS in this issue, with contributions not only from Canada, but also from Hong Kong, Italy, and Brazil, which seek to place the recent global alert in a context that includes historical understanding of dominant approaches to public health.

See pages $642,643,652,655$

Our Speaker's Corner introduces the first of a series on the contribution of women to occupational health. We hope that this series will be an inspiration to young women (and men) to make their contribution in this important area. We begin with Sophia Kisting of Cape Town. And from Shanghai, we have a visual reminder of the importance of fundamental environmental health-in this case, relating to meat.

See pages $645,646,658$
Does Health Impact Assessment need assessment? Krieger and colleagues think so, while Thomson et al give us an example from Glasgow on the wider health benefits from community swimming pools. We also carry a Glossary on Health Impact Assessment this month in our Continuing Professional Education section.

See pages $647,659,663$

The feel of this issue seems to be different, continuing to head in the direction that we set out. The papers on Evidence Based Public Health Policy and Practice and those on research findings seem to be converging. The balance between purely aetiological papers and those with a practical orientation seems to be changing. Many of the research papers now have clearer implications for practice. The menu of papers from both those sections includes:

- bicycle helmet campaigns and poverty;

- requests for out of hours consultations in general practice (issues of equity);

- peer pressure and smoking prevention in adolescence in a school setting;

- and a set of papers on health inequalities relating to childhood and later life.

See pages $668,673,675,681-704$

It seems, too, as if the papers on inequalities are becoming more practically orientated.

These highlighted papers give a flavour from this very full issue, which will hopefully help us to catch up on some of our backlog of unpublished papers. In one sense, we are a victim of our own success, having gone from bimonthly to monthly and having greatly streamlined the turn around of papers submitted, the numbers we are receiving continue to rise. We hope that the selection we are able to publish seems relevant to readers' needs. You can see what forthcoming papers we will be carrying by logging on to our web site at www.jech.com and clicking on "Future Content".

Finally, a footnote to our series on the "Ideal Health Minister", which we published last year. In a letter, Dimoliatis argues the ideal Minister of Health should have a Masters of Public Health qualification. Do we believe in born Ministers of Health? he asks. I suppose the facetious response would be to quote Shakespeare, for while some may be born with a public health understanding, others strive to achieve it, and I suppose not infrequently ministers have it thrust upon them. Perhaps the real issue is whether the management model is appropriate for the ministerial role, and we need to be careful about confusing management with leadership.

See pages 755 